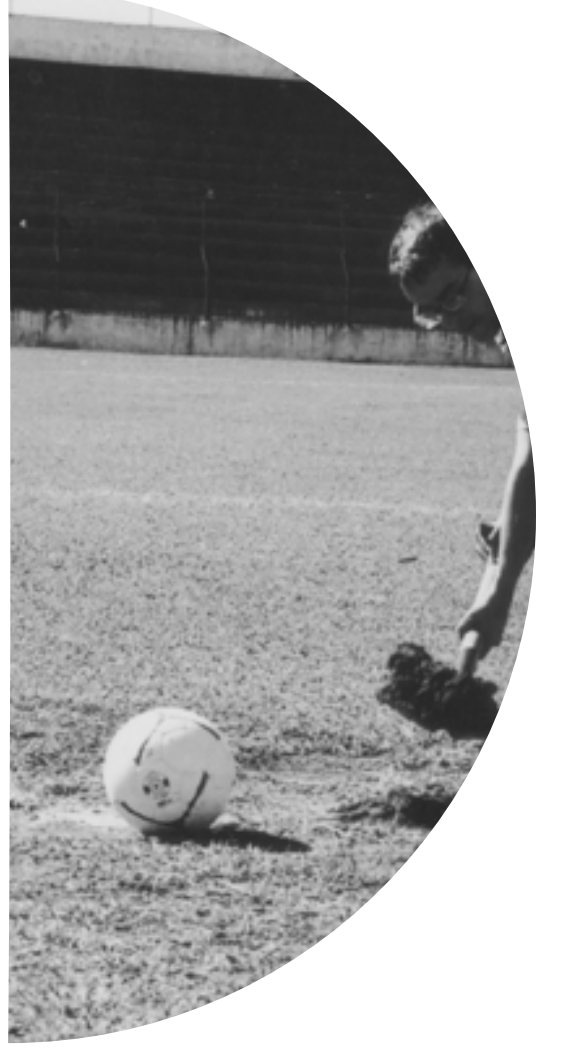

\title{
UM A ZERO
}

\section{Pablo Lobato*}

$2012 ; 2013$

Impressão mineral sobre papel de algodão

$80 \times 80 \mathrm{~cm}$

A série fotográfica Um a zero nos mostra o instante glorioso do gol, por um intervalo breve de tempo, toda a malha hexagonal, antes regular, reage às reverberações e conforma uma nova configuração que percorre sua fibra antes que recupere repouso. Interessa ao artista, nessa topografia instantânea que se desenha, a incorporação de uma geometria flexível, sensual, plena em suas potências mais urgentes de desarranjo.

(Júlio Martins, trecho adaptado de texto publicado originalmente no catálogo Do corte: exposição individual de Pablo Lobato. Luciana Brito Galeria, São Paulo, 2012, p. 27).

* Artista plástico e cineasta. Nasceu em Bom Despacho-MG (1976). Vive e trabalha em Belo Horizonte. E um dos criadores da Teia - Centro de Pesquisa Audiovisual, em Belo Horizonte. Codirigiu, com Cao Guimarães, o longa-metragem Acidente (2002), premiado no Festival de Guadalajara, México. Foi selecionado pelo projeto Bolsa Pampulha (2008), e pelo programa Rumos Artes Visuais (2011-2013). Dirigiu o filme Ventos de Valls (2013), que deriva de uma pesquisa em arte financiada pela fundação Guggenheim.

lobatopa@gmail.com 


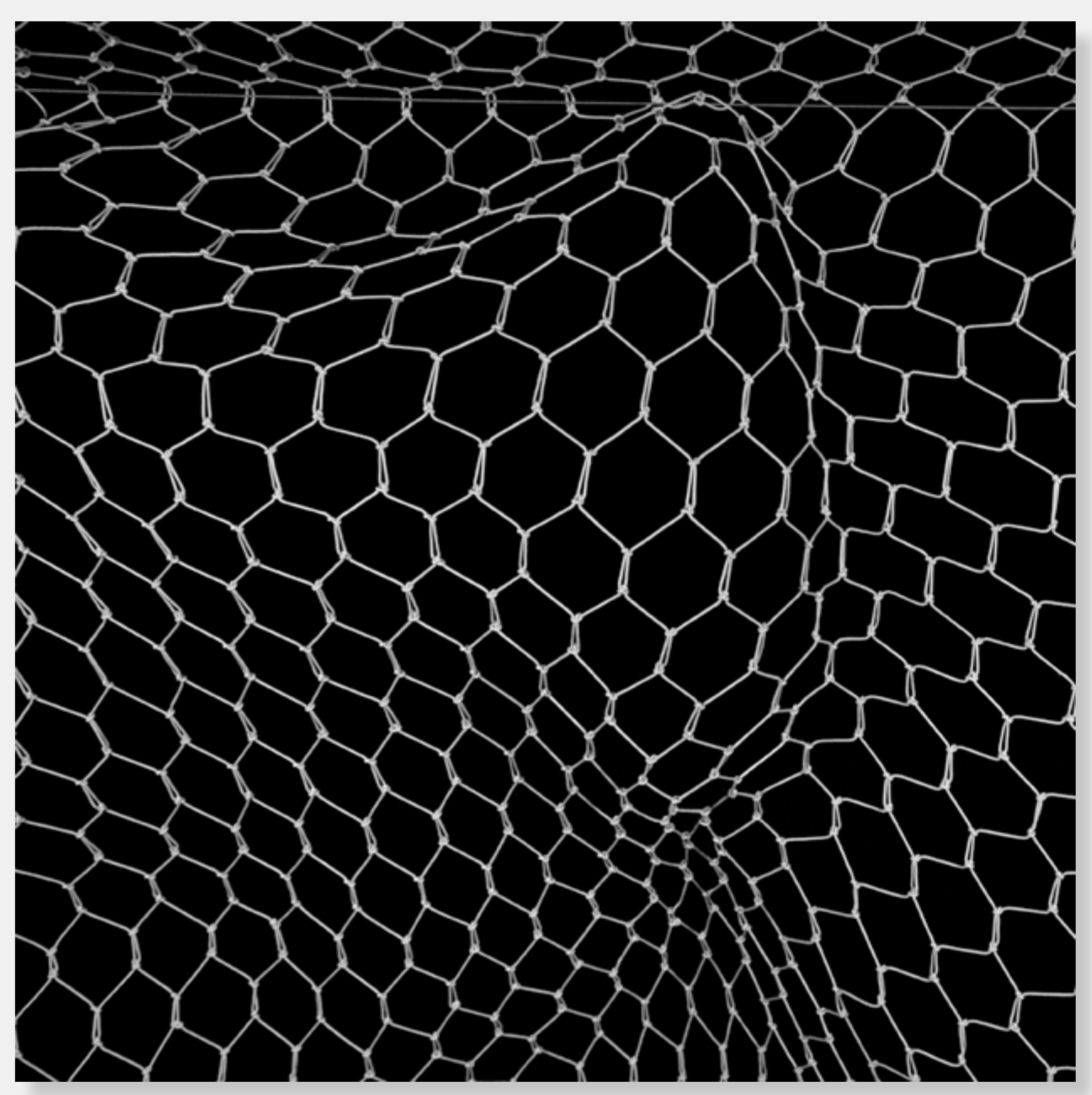

Um a zero \#1, 2012

te algodão $80 \times 80 \mathrm{~cm}$ 


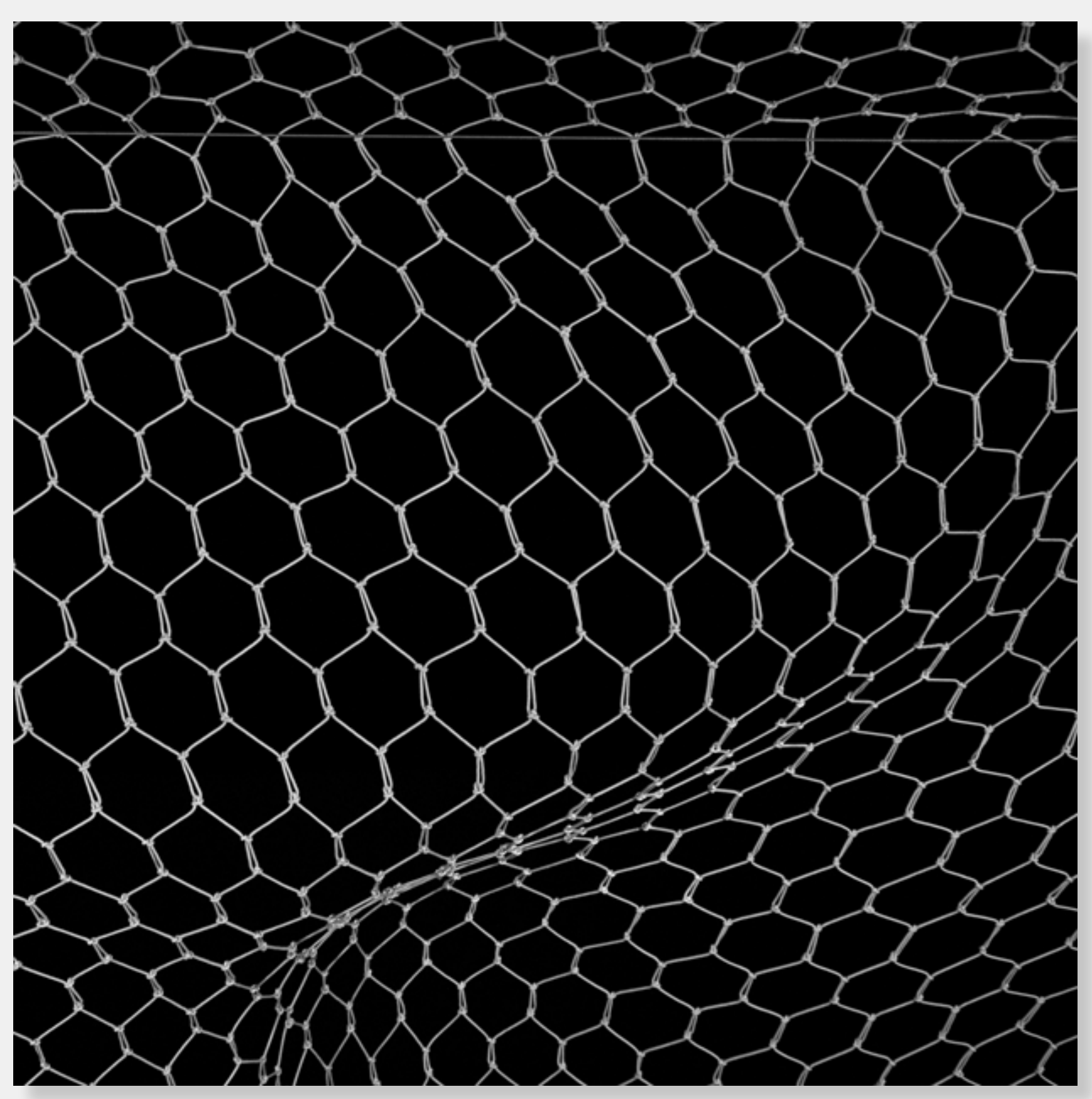

Um a zero \#2, 2012

Imprescão mineral sobre papel de algodão 


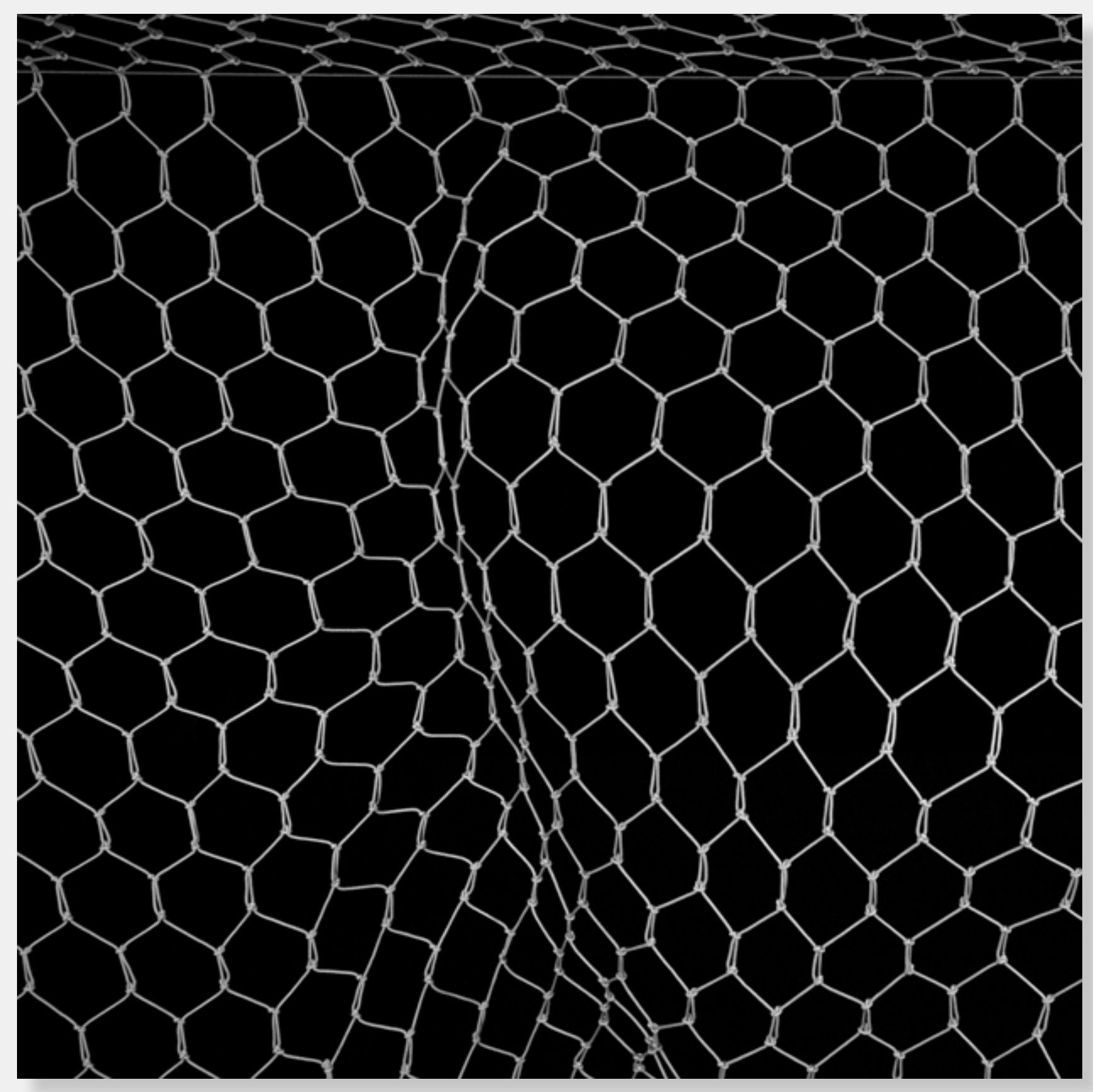

Um a zero \#3, 2012

Impressão mineral sobre papel de algodão 


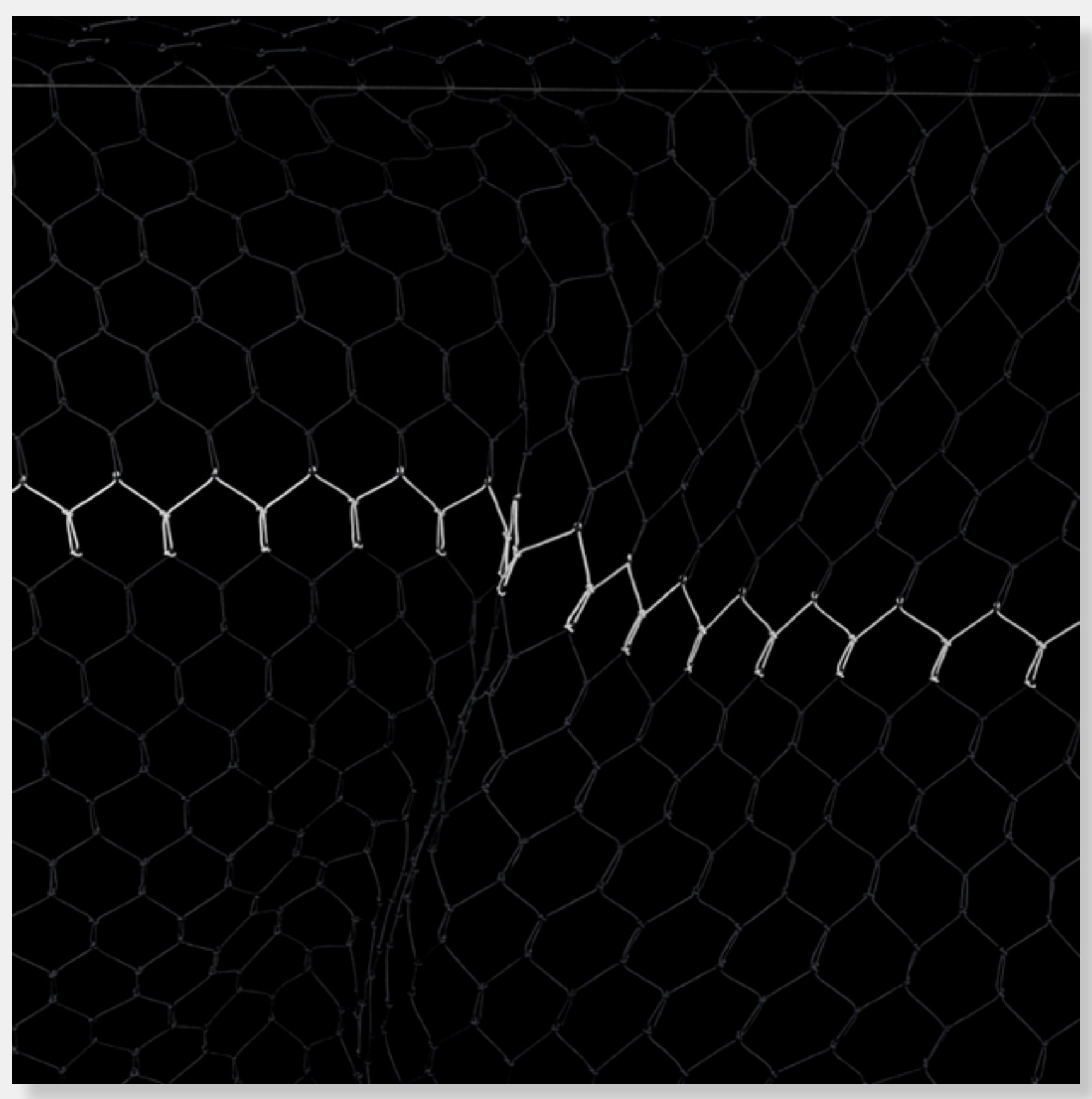

Um a zero \#4, 2012

mpressão mineral sobre papel de algodão
$80 \times 80 \mathrm{~cm}$ 


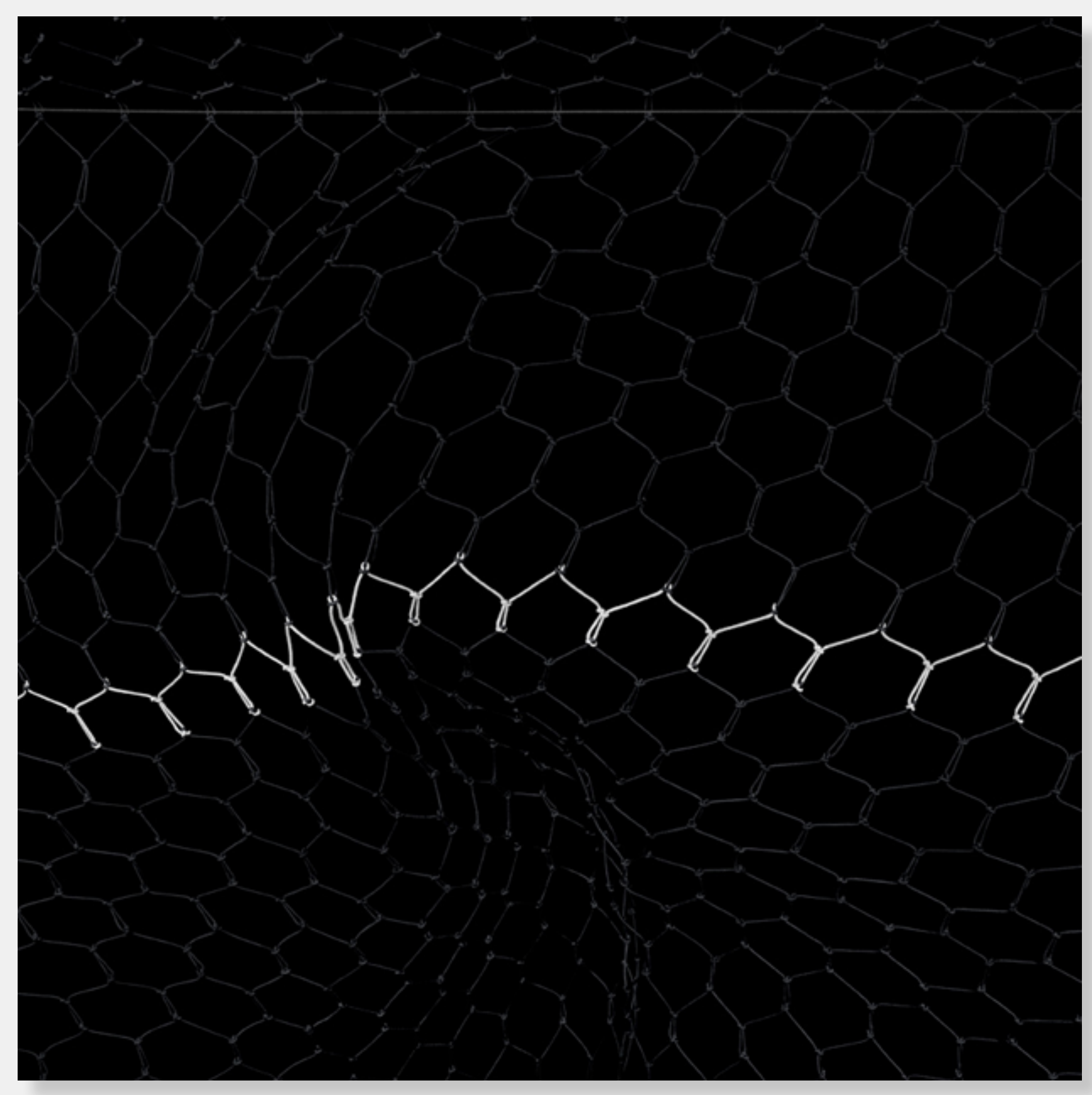

Um a zero \#5, 2012

mpressão mineral sobre papel de algodão

Poéticas 